\title{
ATIVIDADE ANTIFÚNGICA DE ÉSTERES BENZÓICOS E RELAÇÃO ESTRUTURA-ATIVIDADE (REA)
}

\author{
C.S.M. BEZERRA-FILHO ${ }^{1}$, J.N. BARBOZA ${ }^{1}$, A.F.M. MONTEIRO ${ }^{1}$, T.C.LIMA ${ }^{2}$, A.R. \\ FERREIRA $^{1}$, M. C. MORAIS ${ }^{1}$, R.H. N. SILVA ${ }^{1}$, A. J. M. S. OLIVEIRA ${ }^{1}$, C.R.SILVA ${ }^{3}$, \\ R.S. CAMPOS ${ }^{3}$, J.B. A. NETO ${ }^{3}$, H.I. F. MAGALHÃES ${ }^{1}$, H.V. N. JÚNIOR ${ }^{3}$, B. \\ C.CAVALCANTI ${ }^{4}$, D.P. DE SOUSA ${ }^{1^{*}}$
}

\begin{abstract}
${ }^{1}$ Departamento de Ciências Farmacêuticas, Universidade Federal da Paraíba, CEP 58051-970, João Pessoa, Paraíba, Brasil

${ }^{2}$ Departamento de Farmácia, Universidade Federal de Sergipe, CEP 49100-000, São Cristóvão, Sergipe, Brasil

${ }^{3}$ Departamento de Análise Clínica e Toxicológica, Escola de Farmácia, Laboratório de Bioprospecção e Experimentos em Leveduras, LABEL, Universidade Federal do Ceará, Fortaleza, CE, Brasil.

${ }^{4}$ Departamento de Fisiologia e Farmacologia, Universidade Federal do Ceará, Fortaleza, CE, Brasil

$$
\text { E-mail para contato: damiao_desousa@yahoo.com.br }
$$
\end{abstract}

RESUMO - Nos últimos anos, tem havido um aumento dramático na prevalência e gravidade das doenças fúngicas sistêmicas. Assim, o objetivo deste estudo foi avaliar o potencial antifúngico de ésteres do ácido benzoico frente à três espécies da Candida. Os compostos foram preparados via esterificação de Fischer e o teste antifúngico foi realizado pelo método de microdiluição em microplacas de 96 poços para determinar as concentrações inibitórias mínimas (CIM). Os resultados dos testes antifúngicos revelaram que o composto bifenil-3-carboxilato de metila mostrou uma atividade antimicótica interessante contra todas as cepas de Candida testadas, com valores de CMI de 62,5 $\mu \mathrm{g} / \mathrm{mL}$. Além disso, realizou-se um estudo preliminar da Relação Estrutura-Atividade dos ésteres benzóicos, que permitiu o reconhecimento de alguns requisitos estruturais importantes para a atividade antifúngica.

Palavras chave: Atividade antimicrobiana, Candida, Ácidos benzóicos, Produtos naturais

ABSTRACT - In recent years, there has been a dramatic enhancement in prevalence and severity of the systemic fungal diseases. Thus, the aim of this study was to evaluate the antifungal potential of ester derivatives of the benzoic acid against three Candida species. The compounds were prepared via Fischer's esterification and the antifungal assay was performed by the microdilution method in 96-well microplates to determine minimum inhibitory concentrations (MIC). The results of the antifungal tests revealed that the methyl biphenyl-3-carboxylate 
compound shows interesting antifungal activity against all Candida strains tested, with MIC values of $62.5 \mu \mathrm{g} / \mathrm{mL}$. In addition, a preliminary study of the StructureActivity Relationship of benzoic acid derivatives was carried out, which allowed the recognition of some important structural requirements for antifungal activity.

Key words: Antimicrobial activity, Candida, Benzoic acids, Natural products.

\section{INTRODUÇÃO}

Nos últimos anos, a incidência de infecções fúngicas sistêmicas aumentaram, bem como sua gravidade, principalmente em indivíduos imunocomprometidos. Devido às limitações das terapias antifúngicas atuais, bem como o aumento da resistência antimicrobiana, há a necessidade de se investir no desenvolvimento de novos agentes antifúngicos, principalmente em agentes de amplo espectro e com mecanismos de ação inovadores (SHARANAPPA, 2013).

As espécies do gênero Candida estão amplamente distribuídas na natureza, onde algumas fazem parte da microflora humana. Os compostos benzóicos constituem uma ampla classe de metabólitos secundários, possuindo uma variedade de propriedades biológicas. Pode-se verificar que estes compostos foram eficientes no tratamento de micoses sistêmicas e superficiais em humanos (Faria et al., 2016). Estudos publicados na literatura demonstram que o ácido benzóico e seus derivados possuem um importante papel na atividade antifúngica (AMBOBARÉ et al., 2002). Desse modo, o objetivo deste estudo foi investigar o potencial antifúngico de um conjunto de ésteres benzóicos frente à três cepas de Candida. Além disso, também foi examinada a relação estrutura-atividade (REA) dos compostos preparados.

\section{MATERIAIS E MÉTODOS}

\section{Procedimento geral para a preparação dos ésteres}

Uma mistura do ácido orgânico $(0,5 \mathrm{~g})$, metanol $(100 \mathrm{ml})$ e ácido sulfúrico $(0,8 \mathrm{ml})$ foi submetida ao aquecimento sob refluxo. O término da reação foi verificado por CCDA. Em seguida, o metanol foi evaporado sob pressão reduzida, e o produto reacional foi extraído com $30 \mathrm{~mL}$ de acetato de etila e $20 \mathrm{ml}$ de água. Após isso, a fase orgânica foi neutralizada com bicarbonato de sódio a 5\%, tratada com água destilada $(15 \mathrm{~mL})$, seca com sulfato de sódio anidro e filtrada. Após este procedimento, evaporou-se o solvente novamente, obtendo-se os ésteres (FARIAS et al., 2016).

\section{Atividade antifúngica in vitro}

O teste de susceptibilidade antifúngica foi realizado através do método de microdiluição em caldo, de acordo com o protocolo M27-A3 (CLSI, 2008), utilizando o caldo de RPMI ( $\mathrm{pH} 7,0)$. Previamente, os compostos foram dissolvidos em DMSO e os testes foram realizados em concentrações que variaram de 1,95 a $1000 \mu \mathrm{g} / \mathrm{mL}$. As leveduras e os compostos foram incubados em placas de 96 poços a $35^{\circ} \mathrm{C}$ por $24 \mathrm{~h}$ e os resultados foram avaliados visualmente. A concentração mínima de inibição (CMI) de cada composto foi determinada como a concentração que inibiu $50 \%$ do crescimento fúngico. Os microorganismos utilizados neste estudo foram Candida krusei ATCC 6258, Candida albicans ATCC 10231 e Candida parapsilosis ATCC 22019 


\section{RESULTADOS E DISCUSSÃO}

Na presente investigação, foi avaliada a atividade antifúngica in vitro de uma série de nove ésteres benzóicos com diferentes substituições no anel aromático, frente à três espécies de Candida. Os resultados da CMI $(\mu \mathrm{g} / \mathrm{mL})$ dos compostos estão representados na Tabela 1.

Tabela 1 - Concentração mínima inibitória (CMI) dos ésteres 1-9.

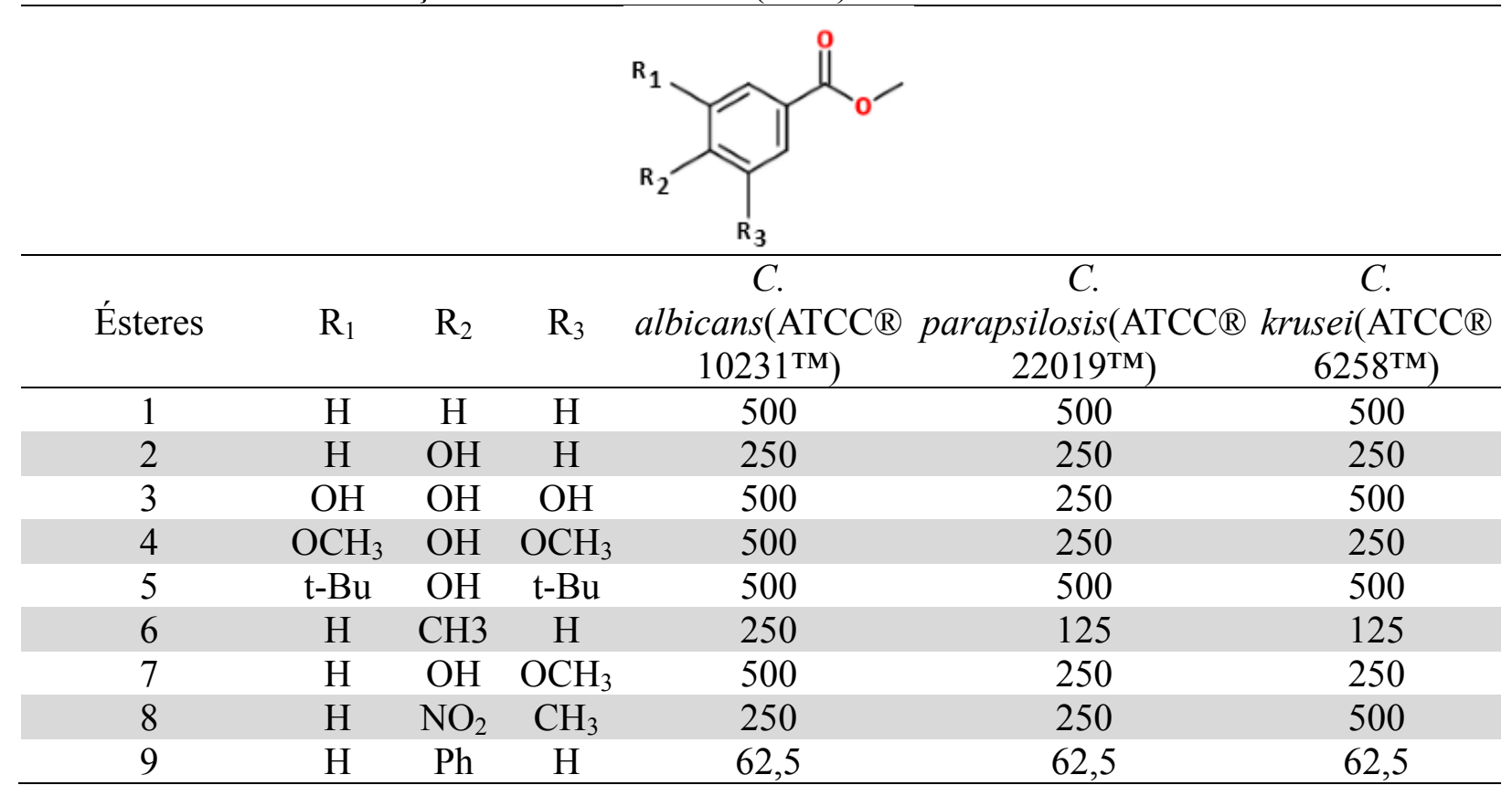

Entre os derivados de ésteres avaliados, verificou-se que o bifenil-3-carboxilato de metila (9) $(\mathrm{CMI}=62,5 \mu \mathrm{g} / \mathrm{mL})$ apresentou a melhor atividade antifúngica em relação às cepas de Candida testadas. Enquanto, o 3,5-di-terc-butil-4-hidroxibenzoato de metila (5) e o benzoato de metila(1) foram os compostos menos ativos, com valores de CMI de $500 \mu \mathrm{g} / \mathrm{mL}$.

A adição de um grupo hidroxila no anel aromático, em geral, resultou em maior ação antifúngica. Por exemplo, quando se comparou a atividade dos compostos benzoato de metila (1) e 4-hidroxibenzoato de metila (2) notou-se que apresentaram diferentes atividades, uma vez que (2) $(\mathrm{CMI}=250 \mu \mathrm{g} / \mathrm{mL})$ foi mais bioativo do que (1) (CMI $=500$ $\mu \mathrm{g} / \mathrm{mL})$. No entanto, a introdução de um segundo ou terceiro grupo hidroxila no anel de aromático diminuiu o efeito antifúngico. Pois, o composto galato de metila (3) $(\mathrm{CMI}=$ $250-500 \mu \mathrm{g} / \mathrm{mL}$ ) foi menos potente do que o 4-hidroxibenzoato de metila (2) (CMI $=250$ $\mu \mathrm{g} / \mathrm{mL}$ ). Ambobaré e colaboradores (2002), relataram que a introdução de mais um grupo hidroxila em diferentes posições no anel aromático dos derivados de ácido benzóico diminuiu a atividade antifúngica frente à Eutypa lata.

No que diz respeito à substituição aromática dos ésteres benzóicos, verificou-se que o aumento de grupos metoxila no anel aromático não afetou o efeito antifúngico, uma vez que os compostos siringato de metila (4) e vanilato de metila (7) exibiram a mesma atividade $(\mathrm{CMI}=250-500 \mu \mathrm{g} / \mathrm{mL})$. Entretanto, a introdução de substituintes de alquila volumosos no anel aromático resultou em diminuição do efeito antifúngico. Por exemplo, o composto 3,5-di-terc-butil-4-hidroxibenzoato de metila (5), com dois grupos tercbutila, foi menos potente $(\mathrm{CMI}=500 \mu \mathrm{g} / \mathrm{mL})$ do que os compostos (3) e (4) (CMI = 250$500 \mu \mathrm{g} / \mathrm{mL}$ ). Esta diminuição no efeito antifúngico provavelmente ocorreu devido ao impedimento estérico. A adição de um grupo $\mathrm{NO}_{2}$ como no composto 3-metil-4- 
nitrobenzoato de metila (8) $(\mathrm{CMI}=250-500 \mu \mathrm{g} / \mathrm{mL})$ foi menos bioativo do que o $p$ toluato de metila (6) $(\mathrm{CMI}=125-250 \mu \mathrm{g} / \mathrm{mL})$.

\section{CONCLUSÃO}

Neste estudo, pode-se investigar a atividade antifúngica de ésteres derivados de ácidos benzóicos, frente à três diferentes cepas de Candida. Os resultados dos testes antifúngicos revelaram que o composto bifenil-3-carboxilato de metila mostrou uma atividade antimicótica interessante contra todas as cepas de Candida testadas, com valores de CMI de $62,5 \mu \mathrm{g} / \mathrm{mL}$. Os requisitos estruturais que influenciam na atividade antifúngica também foram estabelecidos.

\section{REFERENCIAS}

AMBORABÉ, B.E; FLEURAT-LESSARD P; CHOLLET, J. F.; ROBLIN, G. Antifungal effects of salicylic acid and other benzoic acid derivatives towards Eutypalata: structureactivity relationship. Plant Physiol. Biochem v.40, p.1051-1060. 2002.

CLINICAL AND LABORATORY STANDARDS INSTITUTE (CLSI). Reference Method for Broth Dilution Antifungal Susceptibility Testing of Yeasts; CLSI Standard M27-A3; 2008

FARIA N.C.G, KIM J.H, GONÇALVES L.A.P, MARTINS M.L, CHAN K.L, CAMPBELL B.C. Enhanced activity of antifungal drugs using natural phenolics against yeast strains of Candida and Cryptococcus. Lett. Appl. Microbiol v.52, p5. 506-513. 2011

FARIAS M.O, LIMA T.C, PÉREZ A.L, SILVA R.H.N, OLIVEIRA A.J.M.S, LIMA E.O, SOUSA D.P. Antifungal Activity of Ester Derivatives from Caffeic Acid against Candida Species. Ijppr. Human v.7, p. 151-159. 2016.

SHARANAPPA R, VIDYASAGAR, G.M. Anti-Candida activity of medicinal plants: a review. Int. J. Pharm. Pharm. Sci. v.5, p.9-16. 2013.

\section{AGRADECIMENTOS}

Esta pesquisa foi apoiada pelo Conselho Nacional de Desenvolvimento Científico e Tecnológico (CNPq), pela Coordenação de Aperfeiçoamento de Pessoal de Nível Superior (CAPES), pela Universidade Federal da Paraíba e pela Fundação de Apoio à Pesquisa e Inovação Tecnológica do Estado de Sergipe (FAPITEC/SE). 